\title{
Trajetória da gestão por competências na administração pública: um enfoque no contexto da reforma administrativa do estado brasileiro
}

Este trabalho tem como objetivo analisar a evolução da Gestão de Pessoas na Administração Pública sob o contexto de dois modelos de gestão, o gerencial e o societal, quanto à perspectiva da Nova Política de Recursos Humanos, centrada no Plano Diretor da Reforma do Aparelho do Estado, e seu posterior desdobramento com a implantação da Gestão por Competências (GPC), introduzida por meio do Decreto 5.707/2006. Assim como trazer reflexões sobre os aspectos de contribuição e limites da GPC no ambiente público. Para tanto foi realizada revisão bibliográfica baseada em livros e artigos publicados em encontros, congressos e revistas encontradas ao se pesquisar os termos 'reforma do estado'; 'gestão pública'; 'gestão por competências na gestão pública', 'recursos humanos', 'reformas administrativas' e 'gestão social'.

Palavras-chave: Reforma do estado; Setor público; Gestão por competências; Recursos humanos.

\section{The Trajectory of competence-based management in public administration: a focus in the Brazilian's administrative reform context}

\begin{abstract}
This essay aims to analyze the evolution of Human Resources Management in Public Administration under the context of two management models, the manageria and the 'societal' model, regarding the perspective of the New Human Resources Policy, centered on the Master Plan for the Reform of the State Apparatus, and its subsequent development with the implementation of Management by Competences (MBC), introduced by Decree 5.707 / 2006 . As well as showing reflections on the aspects of $\mathrm{MBC}$ contribution and its limits in the public environment. To do so, a bibliographic review was carried out based on books and articles published in meetings, congresses and magazines by researching the terms 'state reform'; 'public Management'; 'Management by competences in public management',

'human resources', 'administrative reforms' and 'social management'.
\end{abstract}

Keywords: State reform; Public sector; Competency management; Human resources.

Topic: Gestão Pública

Reviewed anonymously in the process of blind peer.
Received: 04/04/2021

Approved: 06/06/2021

Thatiana Pedroso Pereira Monteiro Oiticica (iD

Universidade Federal de Alagoas, Brasil

http://lattes.cnpq.br/5062537027186295

http://orcid.org/0000-0001-5655-1256

thatiana.monteiro@gmail.com

Milka Alves Correia Barbosa (id

Universidade Federal de Alagoas, Brasil

http://lattes.cnpq.br/7096185901729086

http://orcid.org/0000-0002-8114-0333

milka.correia@feac.ufal.br

Referencing this:

OITICICA, T. P. P. M.; BARBOSA, M. A. C.. Trajetória da gestão por competências na administração pública: um enfoque no contexto da reforma administrativa do estado brasileiro. Revista Brasileira de Administração Científica, v.12, n.2, p.147-160, 2021. DOI: http://doi.org/10.6008/CBPC2179-684X.2021.002.0013 


\section{INTRODUÇÃO}

O Brasil, no decorrer das últimas três décadas, passou por um período de grandes mudanças estruturais. Observa-se que desde a sua redemocratização, logo após o fim do período militar, ocorreu a tentativa de implantar ações que objetivaram contribuir com o fortalecimento e crescimento do país, como a remodelação de planos econômicos e readequação do arcabouço legal, inaugurando um novo momento para o governo brasileiro, cujos focos tinham como problemas a crise fiscal, crise na forma de intervenção estatal e na sua configuração burocrática de administração.

Este contexto de renovação na gestão pública fez surgir a necessidade de reforma administrativa no Estado ainda em 1995, no governo de Fernando Henrique Cardoso, com o surgimento do Plano Diretor da Reforma do Aparelho do Estado, protagonizado por Luiz Carlos Pereira Bresser, então ministro da Administração Federal e Reforma do Estado, como um novo modelo de desenvolvimento pautado no ideal gerencialista e em seus conceitos de administração e eficiência. Essa fase denominada de Nova Gestão Pública teve como pressupostos a efetividade e a qualidade na prestação dos serviços públicos orientados ao atendimento das necessidades e anseios do cidadão (ABRUCIO, 1997).

A reforma do Estado, nos moldes do Plano Diretor (BRASIL, 1995), abarcou não somente aspectos de economia financeira, mas como também buscou organizar as instituições governamentais e o capital humano que nelas se encontravam. Neste cenário, o Estado passou a abandonar algumas funções ao passo que começou a adotar outras como a regulação, a representatividade política, a justiça e a solidariedade, além de assumir um perfil mais inovador e democrático (PIMENTA, 1998).

Diante desse reposicionamento administrativo adotado pelo governo da época, uma das falhas percebidas foi a falta de uma política de recursos humanos alinhada às necessidades estatais, conforme apontado no Plano Diretor (BRASIL, 1995). O que se tinha era a existência de uma legislação que indiscriminava o uso do instituto da estabilidade de servidores públicos civis e a aplicação de critérios rígidos de seleção e contratação de pessoal que pouco valorizavam o estímulo à competência. Observou-se também que tais práticas contribuíram para limitar "a capacidade operacional do governo ao dificultar a adoção de mecanismos de gestão de recursos humanos que sejam baseados em princípios de valorização pelo efetivo desempenho profissional e também eficazes na busca da melhoria dos resultados das organizações e da qualidade dos serviços prestados" (BRASIL, 1995).

Ressalta-se que o progresso da gestão de pessoas no Brasil está ligado aos principais modelos administrativos: o patrimonialismo, a burocracia e o gerencialismo. Visto que "o nascimento do funcionalismo público no Brasil se confundiu com a própria formação do Estado Brasileiro" (BANDEIRA et al., 2017). Salienta-se que para fins deste trabalho, será abordado apenas o modelo gerencial, visto a sua relevância para o aprimoramento da gestão de pessoas no Brasil.

Assim, em consonância com Nova Gestão Pública e com a proposta de se implantar uma gestão de recursos humanos na Administração Pública, Bresser-Pereira (1998) projetou a Nova Política de Recursos Humanos (NPRH), que tinha como escopo adequar os recursos humanos ao novo Estado ao utilizar-se de 
práticas do meio privado,

implicando o estabelecimento de uma política voltada para a captação de novos servidores, o desenvolvimento ou capacitação do pessoal, a implantação de um sistema remuneratório adequado que estimule o desempenho por meio de incentivos e a instituição de carreiras compatíveis com a necessária reconstrução do aparelho do Estado. (BRESSER-PEREIRA, 1998)

Em 2002, ainda durante a implantação da NPRH, o Brasil passou por uma nova mudança desencadeada pela troca de governo, o qual buscou implantar um novo modelo de desenvolvimento governamental baseado na participação cidadã democrática, na reinvenção político-institucional e na renovação do perfil dos administradores públicos (PAULA, 2005a). A esse posicionamento deu-se o nome de modelo societal, ou social, que é definido como uma gestão que tem sua finalidade voltada para o social, promovida pela própria sociedade e orientada pelos princípios de ética e solidariedade.

No contexto da gestão de recursos humanos, o modelo em contento inovou ao publicar o Decreto no 5.707 de vinte e três de fevereiro de 2006, que instituiu a política e as diretrizes para o desenvolvimento de pessoal da administração pública federal direta, autárquica e fundacional, além de regulamentar dispositivos da Lei 8.112 de 1990. Tal instrumento inaugura no serviço público a Gestão por Competências (GPC) que tem como objetivo promover ações de capacitação focadas nas competências de cada órgão público de modo que o servidor seja devidamente qualificado em sua função (CONCEIÇÃO, 2010).

Frente a essa mudança de pensamento em relação ao desenvolvimento do capital humano impulsionado pela Reforma do Aparelho do Estado e sua evolução para GPD, este artigo busca analisar a Nova Política de Recursos Humanos e a implantação da GPD, contextualizadas sob os modelos gerencial e societal.

Para o estudo aqui proposto procurar-se-á apresentar a evolução da gestão de pessoas no setor público perpassando por dois momentos da reforma administrativa, ou melhor, primeiramente pelo modelo gerencial e logo em seguida pelo societal e, em seguida, a análise e discussão acerca dos cenários encontrados e que contribuíram tanto positiva quanto negativamente para a evolução do tema na administração pública brasileira. Pretende-se também, com este trabalho, que o gestor público, ao compreender o histórico e os avanços obtidos na gestão por competências implantada na administração pública, consiga vislumbrar novas alternativas, sempre com o intuito de aprimorá-la cada vez mais.

\section{METODOLOGIA}

O presente trabalho tem o objetivo de analisar o avanço percebido na gestão pública quanto à gestão de recursos humanos sob o contexto de dois modelos administrativos, o gerencial e o societal.

Conforme classificação feita por Sampieri et al. (2013), do ponto de vista de seus objetivos e da abordagem, esta pesquisa define-se como exploratória e qualitativa, visto que tem a finalidade de proporcionar maiores entendimentos sobre o assunto investigado por meio de métodos não estatísticos. Quanto ao aspecto de procedimentos técnicos, a coleta de dados foi realizada por meio de pesquisa bibliográfica, com o levantamento de livros e artigos publicados em encontros, congressos e revistas encontradas ao se pesquisar na internet os termos 'reforma do estado'; 'gestão pública'; 'gestão por 
competências na gestão pública', 'recursos humanos', 'reformas administrativas' e 'gestão social' .

\section{Modelo gerencial, reforma da administração pública e a nova política de recursos humanos}

O movimento mundial de reformas administrativas no ambiente público começou a tomar corpo a partir dos anos 1980, sob uma conjuntura de crise fiscal, competição por investimentos privados, demanda por mão de obra qualificada, valoração de preceitos pluralistas e neoliberais, aumento da complexidade de nossas sociedades, dentre outros (SECCHI, 2009).

Ainda conforme Secchi (2009) o conjunto destes eventos somado às críticas feitas ao modelo burocrático weberiano, referidas às suas disfunções de ineficiência, morosidade e autorreferência, até então o ideal de gestão pública, abriu espaço para introdução de estratégias aclamadas pelo setor privado. Convictos dessas críticas, o "movimento gerencialista ganhou terreno e passou a recomendar a substituição do sistema burocrático pelo gerencial” (PAULA, 2005a).

O modelo gerencial discutido por Paula (2005a) no livro "Por uma nova gestão pública", mostra que os estudos acerca da possibilidade de se adotar práticas do meio privado no ambiente público começaram a ser disseminados mundialmente com a ascensão de governos neoconservadores como o de Margareth Thatcher, em 1979 na Inglaterra, e Ronald Reagan, em 1980 nos Estados Unidos, que posteriormente tiveram suas concepções replicadas em países como Austrália e Nova Zelândia, incentivados pela crise do modelo keynesiano e fordista.

De maneira geral, baseado na descrição de Pollit (citado por PAULA, 2005a), o gerencialismo sedimenta-se nas seguintes crenças:

O progresso social ocorre pelos contínuos aumentos da produtividade econômica;

A produtividade aumenta principalmente através da aplicação de tecnologias cada vez mais sofisticadas de organização e informação;

A aplicação das tecnologias se realiza por meio de uma força de trabalho disciplinada segundo o ideal da produtividade;

O management ${ }^{1}$ desempenha um papel crucial no planejamento e na implementação das melhorias necessárias à produtividade;

Os gerentes tem o direito de administrar. (PAULA, 2005a)

No Brasil, a concepção gerencialista tomou força nos anos 90 "com o debate da reforma gerencial do Estado e o desenvolvimento da administração pública gerencial" (PAULA, 2005b). A autora reitera ainda que essa mudança decorreu de pressupostos como: desenvolvimento dependente e associado, estratégias neoliberais de estabilização econômica e estratégias administrativas dominantes no cenário das reformas orientadas para o mercado.

Sob o comando de Bresser-Pereira (1998), realizou-se um diagnóstico da situação brasileira, na qual se constatou que, na composição das despesas governamentais, havia forte participação de gastos com pessoal, bens e serviços, assim como o aumento da ineficiência dos serviços públicos (BRASIL, 1995). Assim,

\footnotetext{
${ }^{1}$ Criado pelo movimento gerencialista e pode ser definido como "um conjunto de pressupostos compartilhados pelas empresas como: a crença numa sociedade de livre mercado; a visão do indivíduo como auto-empreendedor; o culto da excelência como forma de aperfeiçoamento individual e coletivo; o culto de símbolos e figuras emblemáticas, como palavras de efeito (inovação, sucesso, excelência), 'gerentes heróis'; a crença em tecnologias gerenciais que permitem racionalizar as atividades organizadas grupais"(PAULA, 2005a).
} 
o então ministro do Ministério da Administração Federal e Reforma do Estado (MARE) adicionou ao seu escopo de trabalho quatro valiosas indagações (Quadro 1) cujas respostas norteariam as propostas de reforma do Estado.

Quadro 1: Perguntas Básicas utilizadas no Diagnóstico da Administração Pública.

1. O Estado deve permanecer realizando as mesmas atividades? Algumas delas podem ser eliminadas? Ou devem ser transferidas da União para os estados ou para os municípios? Ou ainda, devem ser transferidas para o setor público não-estatal? Ou então para o setor privado?

2. Por outro lado, dadas as novas funções, antes reguladoras que executoras, deve o Estado criar novas instituições?

3. Para exercer as suas funções o Estado necessita do contingente de funcionários existente? A qualidade e a motivação dos servidores são satisfatórias? Dispõe-se de uma política de recursos humanos adequada?

4. As organizações públicas operam com qualidade e eficiência? Seus serviços estão voltados prioritariamente para o atendimento do cidadão, entendido como um cliente, ou estão mais orientados para o simples controle do próprio Estado?

Fonte: BRASIL (1995).

O que se buscava por meio destas indagações era uma forma de concretizar os preceitos almejados à época de reduzir o tamanho do Estado, permitir a livre iniciativa e regulação econômica, bem como possibilitar o aumento da governança e da governabilidade (ANDREWS et al., 1998).

Dentre os esforços do diagnóstico da administração pública, destacam-se como produtos o Programa de Qualidade e Participação (MARE, 1997a), o Programa de Reestruturação e Qualidade dos Ministérios (MARE, 1997b) e a efetivação de uma nova política de recursos humanos (BRESSER-PEREIRA, 1998), na qual concentraremos a nossa atenção.

A implantação de uma nova política de recursos humanos visou atender o item três do Quadro 1 e vem ao encontro da redefinição do papel assumido pelo Estado: a necessidade de controle de despesas, descentralização administrativa e melhoria na prestação dos serviços públicos. Assim, a política estabelecida pelo MARE debruçou-se, essencialmente, sobre dois aspectos: o fortalecimento do núcleo estratégico e a profissionalização dos servidores públicos por intermédio da capacitação. Aliado a isso intentou-se adotar ações que aproximassem o mercado de trabalho do setor público com o privado, como a paridade de vencimentos, reestruturação de carreiras e capacitação ampla e perene para os servidores públicos federais.

A proposta central da nova política de recursos humanos do Governo Federal está na prioridade dada ao recrutamento, capacitação e adequação da remuneração dos servidores de nível superior que realizam atividades exclusivas de Estado", fazendo, assim, parte das "carreiras de Estado" (...) O pressuposto é de que o Estado não necessitará de outro tipo de funcionário, ou necessitará deles em volume consideravelmente menor, uma vez que a maioria das atividades auxiliares ou de apoio deverão ser terceirizadas, e a execução de serviços sociais e científicos, publicizada, ou seja, transferida para organizações públicas não-estatais (BRESSER-PEREIRA, 1998).

Uma das principais mudanças ocorreu com a promulgação da Emenda Constitucional no 18 de 1998 que trouxe o instituto da flexibilização da estabilidade nos cargos públicos, com base na qual os servidores públicos passaram a poder ser demitidos caso apresentassem desempenho insatisfatório na avaliação

\footnotetext{
${ }^{2}$ Bresser-Pereira (1998) definiu como atividades de Estado as relacionadas à formulação, controle e avaliação de políticas públicas, fiscalização e execução das leis, regulação e controle de mercados, política, defesa, procuradoria ou advocacia pública, assessoria direta aos parlamentares e a direção de órgãos do Poder Judiciário.
} 
periódica de desempenho ou fossem exonerados diante da insuficiência orçamentária da administração pública, entretanto, em relação à primeira hipótese é assegurado ao servidor o direito ao contraditório e à ampla defesa em processo administrativo.

Esses dois instrumentos tornaram o ambiente de trabalho no serviço público mais instável ao passo que contribuíram para a implementação da administração gerencial. A possibilidade de demissão favorece a mudança de cultura organizacional em busca do melhor desempenho, enquanto a exoneração por insuficiência orçamentária promove a redução do déficit público. Ademais, outras inovações constitucionais foram inseridas com vistas a diminuir o gasto público com pessoal como: a disponibilidade com remuneração proporcional ao tempo de serviço e o estabelecimento de um teto remuneratório para os servidores públicos (PAULA, 2005a).

Quanto à profissionalização do capital humano, a Administração Pública incluiu quatro elementos básicos no plano de reforma: a política de concursos, a revisão da política remuneratória das carreiras de Estado, a reorganização das carreiras e a política de capacitação (BRESSER-PEREIRA, 1998); a seguir detalhados no quadro 2. Através desses preceitos, notou-se que a gestão pública não pensou apenas no aspecto da economia, mas também primou pela valorização do servidor público.

Quadro 2: Elementos básicos da política de recursos humanos da Administração Pública Federal.

\begin{tabular}{|l|l|}
\hline Concurso & $\begin{array}{l}\text { Estabeleceu política de concursos anuais com previsão de quantitativos para próximos anos, tendo como limite } \\
\text { o número de pessoas necessárias para cada órgão. }\end{array}$ \\
\hline Remuneração & $\begin{array}{l}\text { Diminuição da diferença salarial existente entre os servidores do setor público e seus pares no setor privado com } \\
\text { o intuito de atrair pessoas mais qualificadas; aperfeiçoar instrumentos que associam a remuneração ao } \\
\text { desempenho (associar parte do salário a prêmio por desempenho e tornar um número de cargos de nível DAS } \\
\text { exclusivos para servidores efetivos); manter o impacto orçamentário dos gastos com pessoal sob controle. }\end{array}$ \\
\hline Carreiras & $\begin{array}{l}\text { Redução do número de carreiras, priorizando a sua horizontalização com o objetivo de permitir a mobilização e } \\
\text { alocação mais eficiente de pessoal no futuro. }\end{array}$ \\
\hline Capacitação & $\begin{array}{l}\text { Estabelecimento de uma política de capacitação perene que visa aumentar a competência e empregabilidade } \\
\text { dos servidores. Prevê a oferta de dois tipos de cursos: genéricos com conteúdos uniformes para diferentes } \\
\text { públicos-alvo (gerente, pessoal de apoio, etc.) e cursos específicos relativos à sua área de atuação. Dá autonomia } \\
\text { e responsabilidade aos ministérios e órgãos na capacitação do seu pessoal. Substituição da antiga licença-prêmio } \\
\text { pela licença-capacitação. Criação de rubrica orçamentária específica. }\end{array}$ \\
\hline
\end{tabular}

Fonte: BRESSER-PEREIRA (1998).

Importante reconhecer que a profissionalização do servidor foi impulsionada dentro da administração burocrática, com a Nova República, no governo de Vargas, entretanto a sua principal diferença frente a administração gerencial encontra-se em direcionar o desenvolvimento de pessoas para o atendimento das estratégias governamentais com o objetivo de atingir resultados, considerando-se que a preocupação em relação à capacitação não é mais um fim em si mesma.

Ressalta-se também que esses quatro eixos (Quadro 2) visavam fortalecer e priorizar os servidores de carreira do núcleo estratégico do governo, ou seja, a força de trabalho inserida nas atividades exclusivas de Estado: políticas públicas, diplomacia, defesa, regulação de mercado, fiscalização e controle de leis, dentre outros.

Entretanto, sem desconsiderar os avanços no campo, Camões (2019) mostra que mesmo diante desse entusiasmo para resolver a ineficiência estatal em relação ao seu corpo de servidores, na prática o que se visualizou foi a falta de investimento na profissionalização das pessoas e baixa valorização do trabalho por 
elas realizado, bem como a redução da perspectiva de melhoria na remuneração, o que tornou o vínculo público uma mera fonte de renda adicional, fazendo o movimento inverso do disseminado na iniciativa privada.

\section{Modelo societal e a implantação da GPD no ambiente público}

Com a utilização de pilares gerenciais, a ideia que se dissemina pelo Brasil é de um país mais eficiente, voltado a práticas de mercado e que possivelmente dispõe aos cidadãos serviços públicos de melhor qualidade. Apesar de suas contribuições, autores como Paula (2005), Coelho (2012) e Ribeiro et al. (2013) não dispensam críticas ao modelo quando apontam características que, na prática, ainda necessitam ser superadas: caráter centralizador, distanciamento entre planejamento e execução, dicotomia entre gestão e política, decisão nas mãos de tecnocratas e incompatibilidade entre lógica gerencialista e interesse popular.

A partir de 2002, figurou-se no poder a aliança popular-nacional, protagonizada pelo partido dos trabalhadores em parceria com lideranças de centro-esquerda e parte do empresariado, que trouxe como pano de fundo de suas propostas, na tentativa de romper com o modelo anterior dominante, a concepção participativa da sociedade nas deliberações políticas com vistas a tornar o processo mais democrático e legítimo. O novo Estado centra-se na reivindicação dos cidadãos além de estabelecer canais de participação popular, como fóruns, conselhos e o estabelecimento do orçamento participativo (RIBEIRO et al., 2013).

A essa nova relação Estado-Sociedade, Paula (2005a; 2005b) denominou de vertente societal da Administração Pública ou um novo modelo de desenvolvimento no qual "busca-se criar organizações administrativas efetivas, permeáveis à participação popular e com autonomia para operar em favor do interesse público" (PAULA, 2005a).

Autores como Cançado et al. (2011) indicam que a gestão societal ou gestão social ainda é um termo em construção no Brasil, mas que mesmo assim tem se consolidado no campo da prática, o que, segundo os autores, por vezes tende a ser banalizado ao se considerar em seu conteúdo toda forma de gestão que for distinta da tradicional, isto é, teria o vocábulo um conceito por exclusão.

Com o intuito de delimitar melhor o campo de estudo, Tenório (2011), em suas pesquisas, chegou ao seguinte entendimento "gestão social como o processo gerencial dialógico no qual a autoridade decisória é compartilhada entre os participantes da ação (ação que possa ocorrer em qualquer tipo de sistema social público, privado ou de organizações não-governamentais)" (TENÓRIO, 2011).

Em relação à organização administrativa do Estado, notou-se que houve continuação das iniciativas propostas pela Nova Gestão de Recursos Humanos que visava aproximar o trabalho do setor público com o privado, demonstrando que os representantes do modelo aqui exposto não apresentaram uma proposta consolidada devido a sua incapacidade de estabelecer uma agenda própria voltada à reforma da gestão pública (ABRUCIO, 2007).

Essa continuidade também pôde ser evidenciada na política de recursos humanos. Conforme publicação do Ipea (2011), prosseguiu-se com a rotina de concursos públicos, principalmente para cargos alocados nas atividades-fim que exigem nível superior e com a manutenção do nível de gastos com pessoal. 
A proposta de desenvolvimento dos servidores públicos oficiada pelo governo $\mathrm{FHC}$, que tem por base o modelo gerencial e as práticas do setor privado, recebeu um incremento com a implantação da Gestão por Competências (GPD) na Administração Pública Federal, inaugurada pela publicação do Decreto 5.707 em 2006 que, conforme enunciado em seu art. $1^{\circ}$ institui a Política e as Diretrizes para o Desenvolvimento de Pessoal (PNDP) na administração direta, autarquias e fundações públicas (FEVORINI et al., 2014). Destaca-se que este decreto culminou por ser revogado no ano de 2019, por meio do decreto $n^{\circ} 9.991$ de 2019 , que lhe deu carácter mais técnico e denso.

O modelo baseado em competência favorece o surgimento de um novo desenho de gestão estratégica em recursos humanos que reconhece o gestor público como agente propulsor de mudança nas organizações públicas. Nessa perspectiva, Silva et al. (2013) coloca que esse contexto de valorização do gestor, quando condizente com os objetivos organizacionais, tem como consequência o aumento da qualidade dos serviços prestados e melhoria da imagem percebida pelos cidadãos-usuários.

De acordo com o Relatório de Avaliação da Gestão de Recursos Humanos no Governo, realizado pela OCDE Brasil, a GPD já é utilizada há muitas décadas na administração pública por países como Canadá, Estados Unidos e Reino Unido e , tanto no setor público quanto no privado, tem provado ser um modo eficaz de: "definir as habilidades e comportamentos necessários para que as pessoas façam bem o seu trabalho; e ligar uma série de importantes atividades de gestão de recursos humanos para assegurar que uma organização é composta por pessoas competentes que atuam de forma eficaz" (OECD, 2010).

Bergue (2020) ainda complementa que a GPD, em resumo é 'o conhecimento como o saber desenvolvido e acumulado' (BERGUE, 2020) e que transposta para o serviço público, pode ser reconhecida em duas concepções: da organização e das pessoas. Na primeira, busca-se identificar as competências necessárias para o exercício do cargo para fins de estabelecer políticas de capacitação; na segunda, pretendese mapear as competências existentes para orientar políticas de mobilidade e lotação de servidores.

O próprio Decreto 5.707/2006 também traz o seu conceito, em moldes bastante similares, em seu artigo $2^{\circ}$ :

Art. 2o Para os fins deste Decreto, entende-se por:

(...) II - gestão por competência: gestão da capacitação orientada para o desenvolvimento do conjunto de conhecimentos, habilidades e atitudes necessárias ao desempenho das funções dos servidores, visando ao alcance dos objetivos da instituição. (BRASIL, 2006)

Ao longo das últimas duas décadas, o modo como se geria pessoas passou por grandes transformações como: busca por profissional com perfil mais autônomo e empreendedor; transposição do foco no controle para foco no desenvolvimento e a maior inclusão das pessoas no sucesso do negócio (CHIAVENATO, 2016). As instituições públicas não ficaram de fora desse movimento quando se percebe a ocorrência de fortes investimentos na migração do modelo burocrático para um modelo gerencialista, relacionado a valores de produtividade, orientado para serviços e descentralização, que em geral, voltam-se aos princípios de eficiência e competitividade (SILVA et al., 2013).

Como resposta a essas mudanças organizacionais, a GDP, na visão de Carmo (2015), trabalha pontos chave que objetivam agregar valor à organização por meio do desenvolvimento do seu capital humano: 
definição de atribuições e responsabilidades, alocação das competências necessárias a cada objetivo organizacional, plano de capacitação e de desenvolvimento de carreira, avaliação de desempenho e das ações de desenvolvimento, dimensionamento de quadros e a construção clara de uma escala de remuneração atrelada ao desenvolvimento e complexidade das atribuições e responsabilidades.

De forma geral, com o Decreto 5.707/2006, nota-se o esforço da Administração Pública no sentido de buscar o desenvolvimento de competências dos servidores da administração direta, autárquica e fundacional através da capacitação. Essa distinção fica bastante evidente na divisão 'diretrizes' do PNDP explicitadas no art. 3ำ que, em essência, o serviço público procure formas de incentivar o servidor a participar de cursos de capacitação e atualização profissional que sejam adequados ao melhor desenvolvimento do seu trabalho ao passo que também toma para si a obrigação de manter um plano permanente de ofertas de ensino de aprendizagem de acordo com o Plano Plurianual de governo. Importante frisar que, conforme pondera Silva et al. (2013), "é preciso deixar claro que a implantação da gestão por competências não implica no processo de avaliação de desempenho" (SILVA et al., 2013).

Ademais, utilizando-se do artifício da descentralização e da otimização de recursos, tornou-se possível a celebração de convênios entre instituições federais de ensino e escolas de governo para que aquelas venham a ofertar cursos de capacitação aos servidores de outras instituições (AMARAL, 2006). Indo mais além, pela definição de 'eventos de capacitação' constante no decreto, o autor compreende que houve uma ampliação dos espaços de aprendizagem que agora abarcam cursos tanto presenciais quanto à distância, aprendizagem em serviço, seminários e congressos, estágios, aprendizagem em serviço, grupos formais de estudos e intercâmbio.

Como forma de apoiar a implementação da GPD, foi criado o Comitê Gestor da Política Nacional de Desenvolvimento de Pessoal que tem como competências: avaliar os relatórios anuais dos órgãos e entidades com o objetivo de verificar se foram observadas as diretrizes da PNDP; orientar as entidades a que se destinam os comandos do decreto na definição sobre a alocação de recursos para fins de capacitação de seus servidores; promover a disseminação da PNDP e zelar pela observância do decreto (BRASIL, 2006).

Quanto à ENAPì, entidade instituída no governo de José Sarney, coube a competência de "promover, elaborar, executar ações de capacitação (...) assim como a coordenação e supervisão dos programas de capacitação gerencial de pessoal civil executados pelas demais escolas de governo da administração pública federal direta, autárquica e fundacional” (BRASIL, 2006).

O decreto 5.707/2006, inclusive, regulamentou o art. 87 da Lei 8.112 de 1990 que estabelece o instituto da Licença para Capacitação. Seus dispositivos abrange a possibilidade de o servidor solicitar afastamento para participar de cursos lato sensu e strictu sensu quando não houver compatibilidade de horário com o exercício da atividade laboral, bem como concede licença remunerada por três meses, a cada cinco anos de efetivo exercício, para participar de ação de capacitação.

Outra formalização trazida pelo dispositivo legal em comento foi a necessidade de se 'reservar um percentual fixado a cada biênio pelo Comitê Gestor para atendimento aos públicos-alvo e a conteúdos prioritários, ficando o restante para atendimento das necessidades específicas (BRASIL, 2006). 
Sob a égide do Decreto 5.707/2006, que teve vigência por 12 anos, instituições públicas como Petrobrás, BNDES e o Ministério da Fazenda ${ }^{\text {iï }}$ foram consideradas experiências bem sucedidas na implantação da GPD como estratégia de recursos humanos, segundo relatório da OECD (2010).

Em síntese, percebe-se que a gestão de pessoas teve sua devida importância nos dois modelos de gestão adotados em diferentes épocas no Brasil. A instituição da Nova Política de Recursos Humanos e sua evolução com o incremento da GPD nas organizações públicas, mesmo implantadas em governos de ideologias opostas, acabaram por seguir pelo caminho da eficiência e da satisfação do cidadão-usuário através da melhoria dos serviços prestados. Entretanto, a transposição de práticas do setor privado para o público tende a encontrar críticos e dificuldades práticas que podem tanto depreciar as conquistas organizacionais quanto contribuir para outras inovações que venham a ocorrer futuramente. A seguir será apresentada discussão e análise dos dois contextos apresentados neste tópico e no anterior, assim como propostas de inovações e perspectivas para a gestão de recursos humanos na administração pública.

\section{DISCUSSÃO TEÓRICA}

A inovação na gestão de recursos humanos com a implantação da GPD no serviço público certamente volta os olhos da administração pública para um posicionamento mais estratégico quanto ao modo como o capital humano pode contribuir com as organizações públicas. Entretanto, mesmo diante de casos aceitos como bem-sucedidos, como os exemplos discorridos no referencial teórico, o relatório da OECD (2010) sinaliza a existência de dois pontos considerados obstáculos para a implantação da GDP: a rígida estrutura legal brasileira e a cultura observada no serviço público. Kriiger et al. (2018) ainda acrescentam mais cinco aspectos relevantes a serem considerados neste rol:

Inaptidão técnica dos servidores que lidam diretamente com o tema;

Desconfiança da sua aplicabilidade na administração pública;

Carência de apoio do nível gerencial;

Assincronia entre 'saber fazer', 'como fazer' e 'querer fazer';

Ausência de gestão do conhecimento. (KRIIGER et al., 2018)

O relatório de Avaliação da Gestão de Recursos Humanos no Governo da OECD de 2010 aponta a notória dificuldade de se introduzir a GPD no processo de recrutamento de forma que se possa obter um ajuste ideal entre as necessidades da organização e capacidades das pessoas convocadas. O concurso público tem sido visto como parte do processo legalista constitucional desenhado para cumprir os atributos de mérito e transparência das ações de recrutamento e não como um instrumento capaz de trazer a melhor pessoa para desempenhar o trabalho. Nessa linha, alguns autores em 2017, em sua pesquisa, que teve como objetivo identificar elementos que influenciam na adoção da gestão por competências no serviço público, apontam que nesse aspecto os concursos até conseguem selecionar pessoas academicamente preparadas, mas quando são levadas em consideração habilidades e atitudes, como o trabalhar em equipe e a proatividade, nem sempre essas pessoas conseguem ter uma atuação desejável.

Além disso, neste mesmo estudo, os autores adicionam a constatação de outras dificuldades 
organizacionais ao implantar a GPD: Carência de metodologia capaz de identificar as competências organizacionais e de mapear as competências individuais; Sistema de desenvolvimento profissional, como plano de cargos e carreira, baseados em tempo de serviço ao invés de considerar os resultados obtidos em avaliação de desempenho e competências; Sistema de remuneração desvinculado de resultados.

Diante de todas essas distorções encontradas no ambiente de renovação da gestão pública, Bergue (2011) defende que se devidamente ressignificada para o ambiente das organizações públicas, e não apenas transferida ou adaptada do meio privado, a GPD pode impactar sobremaneira no desenho de cargos públicos, na definição de carreiras e no sistema de remuneração.

Nessa tendência, o autor ainda denota que se considere as competências para o exercício do cargo desejadas pela organização, em detrimento da tentativa de se esgotar o elenco de atividades passíveis de serem desenvolvidas, como atualmente é feito. Alinhado a isso também aponta pela "criação de espaços de desenvolvimento profissional e pessoal de longo prazo que se assentem também nas potencialidades que os agentes não somente trazem, e que extrapolam as exigências mínimas para ingresso, mas aquelas que podem ser desenvolvidas no curso da vida profissional" (BERGUE, 2011).

Quanto ao sistema de remuneração, pouco a pouco a noção de produtividade vem sendo incluída ao permitir a utilização da remuneração estratégica, que, em síntese, permite que a organização utilize variados artifícios remuneratórios para estimular e motivar pessoas, no lugar da tradicional remuneração funcional cujo foco fixa-se no cargo e não na pessoa e em seus atributos. Essa mudança no sistema vislumbra beneficiar o servidor com base nas suas habilidades e entregas (BERGUE, 2020). Porém, ainda é preciso refletir sobre essa questão, visto que a concessão de um estímulo monetário por desempenho pode vir a impactar no orçamento público, assim, há que se considerar a existência de dispositivos legais que permitam tais alterações.

Via de regra de nada adianta implantar, ou ainda cogitar as ideias contempladas por Bergue se antes de tudo não houver a definição de uma metodologia adequada para identificar as necessidades da organização em relação às competências esperadas das pessoas que compõe o seu corpo de trabalho, falha está identificada nos estudos de Kriiger et al. (2018) e que se configura na base para se estruturar a GPD.

Com relação ao Decreto no 5.707 de 2006 e o seu sucessor Decreto № 9.991 de 2019, percebe-se uma forte tentativa por parte da administração pública em elevar, com foco na capacitação, o desempenho de seus servidores para que estes adquiram novas competências ou mesmo desenvolvam as que já possuam. Pela leitura do ato normativo então vigente, constata-se a preocupação em aparar as arestas deixadas pelo instrumento anterior ao passo que incrementa novas configurações à Política Nacional de Desenvolvimento de Pessoas. Define de forma extensa o papel da ENAP nesse processo, releva a instituição do Comitê à medida que transfere ao SIPEC (Sistema de Pessoal Civil da Administração Federal) a competência para orientar e avaliar os demais órgãos e organizações na elaboração e execução de seus Planos de Desenvolvimento de Pessoal, estabelece prazos para implantação, execução e prestação de contas e dispõe regras para a realização de despesas com capacitação e afastamento de servidores para participação em ações de desenvolvimento. 
Em suma, pode-se depreender desta análise que o novo decreto não trouxe mudanças essenciais da GPD no ambiente público, apenas mostrou-se um texto que pormenoriza os dispositivos antes generalizados, ou seja, tornou-se mais denso e cheio de regras burocráticas. Todavia, o maior desafio é fazer com que essa política de recursos humanos se torne cada vez mais factível e não uma ferramenta isolada ou com um fim em si mesma.

De toda forma, autores como Silva e Mello, Bergue, Chiavenato e Amaral, acreditam que a gestão com base em competências no serviço público tem um espaço bastante promissor, que essa abordagem pode, inclusive, ajudar a mudar a cara do serviço público, tão criticado pela sua ineficiência e pelos maus serviços prestados à população. E quando aos contextos de gestão, observa-se que tanto o gerencial quanto o societal, este tido como pano de fundo oficial da implantação formal da GPD, apesar de seus pontos confrontantes em diversos aspectos na administração pública, ambas desenvolveram ações com o propósito de melhorar os recursos humanos do governo, capacitar e evoluir o seu corpo de trabalho.

Diante disso, apesar de todo o esforço feito nos últimos anos e, claro, conquistas concretas, considera-se que o tema ainda precisa ser melhor explorado pela administração pública brasileira, tornandose um desafio para os atuais e futuros gestores públicos.

\section{CONCLUSÕES}

No contexto das reformas administrativas que avançaram no Brasil a partir da implantação do Plano Diretor, a relação Estado-Sociedade e a gestão pública se redefinem sob a tentativa de afastar a dicotomia democracia e eficiência. A abertura para a participação social somada à gestão técnica passa a nortear a reforma da administração pública no país. Assim, as ideias desenvolvidas no arcabouço dos modelos gerencial e societal, apesar de terem contrapontos, não se excluem, mas tão somente há predominância de um molde sobre o outro.

Na evolução das reformas, percebe-se que a própria perspectiva de inclusão social nas deliberações políticas contribui para que as demandas dos cidadãos pela atuação mais satisfatória do Estado sejam levadas mais a sério, tornando-se então mais um instrumento de cobrança de melhoria da gestão governamental. Nesse horizonte toma-se a consciência de que para alcançar os seus objetivos é preciso alinhar o trabalho de governo com as perspectivas e competências desejáveis em seus servidores. Parafraseando Bergue (2020), agir nesta linha é o mesmo que fazer gestão estratégica de recursos humanos.

A nova política de recursos humanos desenvolveu ações focadas em quatro eixos: concurso, remuneração, carreira e capacitação; e que anos mais tarde evidenciou-se serem insuficientes para extrair o melhor desempenho de seu pessoal quando desalinhadas com as finalidades organizacionais, bem como acabaram por surtir o efeito inverso quanto à valorização do servidor em seu trabalho, conforme ponderado por Camões. Em vista disso a GPD, desenvolvida no meio privado, fez-se proposta alternativa pautada em valores e expectativas voltados para um ambiente de aprendizagem.

Atualmente a sistemática disposta em ato normativo alcança apenas o eixo capacitação quando impõe que toda a administração pública federal, autárquica e fundacional deverá definir um plano perene 
de treinamento de servidores, formas de avaliação dos novos conhecimentos adquiridos e as condições para participação. Interessante pontuar que para que se defina um plano de desenvolvimento, o decreto 9.991/2019 foi categórico ao impor que se faça o mapeamento das competências organizacionais necessárias a serem adquiridas dentro desse processo.

Entretanto, o foco no uso da gestão por competências não se limita à capacitação e treinamento, ela pode ser utilizada como guia em diversas outras transformações organizacionais que tendem a trazer mais coesão entre a entrega do servidor e as expectativas da entidade pública. Conforme já foi trazido em tópicos anteriores, a GPD pode subsidiar o desenho de cargos com vistas a melhorar o processo de recrutamento e seleção, definir plano de carreiras baseado em resultados e não em tempo de trabalho, bem como adotar sistemática de remuneração variável que premie o melhor desempenho.

É valioso frisar ainda que para além de boas propostas, A GPD encontra no ambiente público dificuldades inerentes ao seu processo de formação, como a alta carga normativa, que permite pouca flexibilidade frente às ações de uma gestão inovadora e, principalmente, cultural, já que o servidor público não tem o costume de ser cobrado, e agora de maneira mais ativa pelo cidadão, pela qualidade das suas entregas.

Ainda com toda a dificuldade implicada no processo, destacou-se aqui o esforço dispendido por entidades governamentais como Petrobrás e BNDES para se enquadrar nesse cenário de mudança, e que aqui caberiam algumas observações quanto a atuação marcante no mercado privado e cultura organizacional mais receptível, seja a primeira como uma sociedade de economia mista que tem relacionamento com investidores que cada vez mais cobram pela sua eficiência organizacional, seja na segunda que atua como agente de fomento e estímulo econômico que também responde a mandamentos de cunho privado.

Por fim, diante de tudo que foi exposto, constata-se que a GPD é uma sistemática promissora no serviço público, é uma escolha que quando bem aceita e adotada, tende a responder positivamente ao maior desafio em recursos humanos no ambiente público: combinar o potencial dos servidores aos objetivos das instituições resultando na melhoria da prestação dos serviços públicos.

\section{REFERÊNCIAS}

ABRUCIO, F. L.. O impacto do modelo gerencial na administração pública: um breve estudo sobre a experiência internacional recente. Brasília: ENAP, 1997.

ABRUCIO, F. L.. Trajetória recente da gestão pública brasileira: um balanço crítico e a renovação da agenda de reformas. Rev. Adm. Pública, Rio de Janeiro, v.41, p.67-86, 2007. DOI: http://dx.doi.org/10.1590/S003476122007000700005

AMARAL, H. K.. Desenvolvimento de competências de servidores na administração pública brasileira. Revista do Serviço Público, v.57, n.4, p.549-563, 2014. DOI: https://doi.org/10.21874/rsp.v57i4.211

ANDREWS, C. W.; KOUZMIN, A.. O discurso da nova administração pública. Lua Nova, São Paulo, n.45, p.97-129, 1998. DOI: https://doi.org/10.1590/S0102-

\section{$\underline{64451998000300005}$}

BANDEIRA, E. L.; ARRUDA, H. R.; CABRAL, A. C. A.; SANTOS, S. M.. Panorama da gestão de pessoas no setor público. Rev. Pensamento Contemporâneo em Administração, v.1, n.4, p.86-103, 2017. DOI:

https://doi.org/10.12712/rpca.v11i4.1051

BERGUE, S. T.. Gestão por Competências. In: BERGUE, S. T.. Modelos de gestão em organizações públicas: teorias e tecnologias para análise e transformação organizacional. Caxias do Sul: EDUCS, 2011. p.553-569.

BERGUE, S. T.. Gestão estratégica de pessoas no setor público. 2 ed. Belo Horizonte: Fórum, 2020.

BRASIL. Câmara da Reforma do Estado. Plano Diretor da Reforma do Aparelho do Estado. Brasília: Câmara da 
Reforma do Estado, 1995.

BRASIL. Constituição Federal de 1988. Brasília: DOU, 2016.

BRASIL. Decreto no 5.727, de 23/02/2006. Institui a Política e as Diretrizes para o Desenvolvimento de Pessoal da Administração Pública federal direta, autárquica e fundacional, e regulamenta dispositivos da Lei no 8.112, de 11 de dezembro de 1990. Brasília: DOU, 2006.

BRASIL. Decreto no 9.991, de 28/08/2019. Dispõe sobre a Política Nacional de Desenvolvimento de Pessoas da administração pública federal direta, autárquica e fundacional, e regulamenta dispositivos da Lei 8.112, de 11 de dezembro de 1990, quanto a licenças e afastamentos para ações de desenvolvimento. Brasília: DOU, 2019.

BRASIL. Lei Federal 8.112, de 11/12/1990. Dispõe sobre o regime jurídico dos servidores públicos civis da União, das autarquias e das fundações públicas federais. Brasília: DOU, 1997.

BRESSER-PEREIRA, L. C.. A Nova Política de Recursos Humanos. In Bresser-Pereira, Luiz Carlos. Reforma do Estado para a Cidadania. São Paulo: 34, 1998. p.267-279.

CAMÕES, M. R. S.. Inovação em Gestão de Pessoas no Setor Público: reflexão sobre as práticas no contexto brasileiro. Revista de Políticas Públicas e Gestão Governamental, v.16, n.1, 2019.

CANÇADO, A. C.; TENÓRIO, F. G.; PEREIRA, J. R.. Gestão Social: reflexões teóricas e conceituais. Cadernos EBAPE BR, São Paulo, v.9, n.3, p.681-703, 2011. DOI: https://doi.org/10.1590/S1679-39512011000300002

CARMO, L. O.. Gestão de Pessoas baseada em competências: um modelo avançado de gestão. Revista de Administração Geral, v.1, n.2, p.101-117, 2015.

CHIAVENATO, I.. Treinamento e desenvolvimento de recursos humanos: como incrementar talentos na empresa. 7 ed. Barueri: Manole, 2016.

COELHO, F. S.. Reformas e Inovações na Gestão Pública no Brasil Contemporâneo. In: CARNEIRO, J. M. B.; DANTAS, H. Parceria Social Público-Privado: textos de referência. São Paulo: Oficina Municipal, 2012. p.1-376.

\section{CONCEIÇÃO, M. C.. A alternativa da gestão por} competências na administração Pública Federal: uma abordagem teórica. UFRGS, 2010.

FEVORINI, F. B.; SILVA, R. T.; CREPALDI, A. M.. Gestão por competências no setor público: exemplos de organizações que adotaram o modelo. Revista de Carreiras e Pessoas. São Paulo, v.4, n.2, p.128-142, 2014. DOI: https://doi.org/10.20503/recape.v4i2.20577

IPEA. Instituto de Pesquisa Econômica Aplicada. Ocupação no Setor Público Brasileiro: tendências recentes e questões em aberto. Brasília: Comunicado do IPEA, 2011.

KRIIGER, C. C. P. V.; ANDRADE, E. P.; SILVA, A. M.; MOURÃO, C. O.; PIZZOL, R. A.; LIMA, S. T. P.. Desafios à implantação de modelos de gestão por competências em uma autarquia federal. Revista Do Serviço Público, Brasília, v.69, n.3, p.707740, 2018. DOI: https://doi.org/10.21874/rsp.v69i3.1674

MARE. Programa da Qualidade e Participação na Administração Pública. Cadernos MARE, Brasília, n.4, p.62, 1997a.

MARE. Plano de Reestruturação e Melhoria da Gestão do MARE. Cadernos MARE, Brasília, n.5, p.44. 1997b.

OECD. Avaliação da Gestão de Recursos Humanos no Governo. Relatório da OCDE. Brasília: Governo Federal; Paris: OECD Publishing, 2010. DOI: https://doi.org/10.1787/9789264086098-pt

PAULA, A. P. P.. Por uma nova gestão pública: limites e potencialidades da experiência contemporânea. Rio de Janeiro: FGV, 2005a. DOI: http://dx.doi.org/10.1590/S141565552006000200014

PAULA, A. P. P.. Administração pública brasileira entre o gerencialismo e a gestão social. Revista de Administração de Empresas, v.45, n.1, p.36-49, 2005b. DOI: https://doi.org/10.1590/S0034-75902005000100005

PIMENTA, C. C.. A reforma gerencial do Estado brasileiro no contexto das grandes tendências mundiais. Revista de Administração Pública, v.32, n.5, p.173-199, 1998.

RIBEIRO, L. M. P.; PEREIRA, J. R.; BENEDICTO, G. C.. As reformas da Administração Pública brasileira: uma contextualização do seu cenário, dos entraves e das novas perspectivas. In: ENCONTRO ANPAD, 37. Anais. Rio de Janeiro, 2013.

SAMPIERI, R. H.; COLLADO, C. F.; LUCIO, M. P. B. Metodologia de Pesquisa. Porto Alegre: Penso, 2013.

SECCHI, L.. Modelos organizacionais e reformas da administração pública. Rev. Adm. Pública, Rio de Janeiro, v.43, n.2, p.347-369, 2009. DOI: https://doi.org/10.1590/S0034-76122009000200004

SILVA, F. M.; MELLO, S. P. T.. A Implementação da Gestão por Competências: práticas e resistências no setor público. Revista Eletrônica de Administração e Turismo, v.2, n.1, p.110-127, 2013. DOI: https://doi.org/10.15210/reat.v2i1.1959

TENÓRIO, F.. (Re)Visitando o conceito de gestão social. Desenvolvimento em Questão, v.3, n.5, p.101-124, 2011. DOI: https://doi.org/10.21527/2237-6453.2005.5.101-124

A CBPC - Companhia Brasileira de Produção Científica (CNPJ: 11.221.422/0001-03) detém os direitos materiais desta publicação. Os direitos referem-se à publicação do trabalho em qualquer parte do mundo, incluindo os direitos às renovações, expansões e disseminações da contribuição, bem como outros direitos subsidiários. Todos os trabalhos publicados eletronicamente poderão posteriormente ser publicados em coletâneas impressas sob coordenação da Sustenere Publishing, da Companhia Brasileira de Produção Científica e seus parceiros autorizados. Os (as) autores (as) preservam os direitos autorais, mas não têm permissão para a publicação da contribuição em outro meio, impresso ou digital, em português ou em tradução. 